\title{
1 \\ What Was Cancer? Definition, Diagnosis and Cause
}

CANCER, (in Surgery) a dangerous Sore, or Ulcer; as in a Womans Breast, \& c.

DEGENERATE CANCER, is one which succeeds an Obstinate or ill-dressed Imposthume.

PRIMITIVE CANCER, (among Surgeons) is one which comes of it self.

[...]

CARCINODES ... a Tumour like a Cancer.

CARCINOMA ... the Cancer before it comes to an ulcer. ${ }^{1}$

Published in 1721, Nathan Bailey's Universal Etymological English Dictionary demonstrates the complexity of early modern perceptions of, and terms for, cancerous disease. In Bailey's definitions, cancer slips between identification by its prognosis, origins and stage. Not everything that looks like a cancer is a cancer - 'Carcinodes' merely imitates that disease - but it is unclear on what basis one can differentiate between 'real' and false cancers, or spot a cancer in the first place. Moreover, Bailey's dictionary only scratched the surface of the variance seen in texts discussing cancer, which included differences in terminology and definition almost as numerous as those who wrote them down. The project of this chapter, therefore, is to determine how we should understand early modern cancer(s). Can we treat 'cancer' as a single disease, with a single name? What made this disease different from others with similar symptoms? By what other terms might it have been recognised, and how was it identified in early modern medical practice?

In the Introduction to this book, I noted that studies of the history of cancer have often taken a retrodiagnostic approach, applying modern 
medical knowledge to pre- or early-modern experiences of disease. This tendency has been most prominent in the common assumption that Medieval or Renaissance physicians and onlookers possessed a view of cancerous disease which was simply a less sophisticated version of that found in modern medicine, and that they made 'right' or 'wrong' decisions about diagnosis and treatment from that viewpoint. ${ }^{2}$ Even in the latest and most comprehensive study of cancer in the early modern period, Marjo Kaartinen's Breast Cancer in the Eighteenth Century, the focus is firmly on the experience of cancer patients once they had been diagnosed, and as such, the author devotes only 4 of her 124 pages to examining the definition and diagnosis of cancers. ${ }^{3}$ Departing from these treatment-focussed histories of cancer, I will argue that in the long seventeenth century, discussions of the etymological roots, cause, and symptoms of cancer were central to the discursive creation of the disease. Furthermore, these discussions took place in literary as well as medical texts.

To date, analyses of the meaning of terms such as 'canker' and 'cancer' in drama, poetry and polemic have been surprisingly few. One of the most in-depth discussions of the significance of 'canker', Jonathan Gil Harris's article on Gerard Malynes's 1601 A Treatise of the Canker of England's Common Wealth, focuses largely on the disease's connection to the canker-worm, and as such is detailed in Chapter $3 .{ }^{4}$ Lynette Hunter, meanwhile, speculates on the meanings of 'canker' in Romeo and Juliet, and notes how, in that play, the Friar and the Prince 'deal with different kinds of canker: the canker that is the closed-over but ulcerous wound and the canker-worm that consumes the plant from inside its stem'. ${ }^{5}$ While Hunter argues that both kinds of canker 'have the ambivalent potential to be at the same time internal contamination and external infection or contagion', she views medical 'cankers' as referring to ulcerous wounds in general, and thus overlooks the rhetorical potential of malignant cancer, of which ulceration was merely one symptom. ${ }^{6}$ Sujata Iyengar's Shakespeare's Medical Language comes closer than Hunter's analysis to describing the full potential of 'canker' as a term which might describe several kinds of horticultural or bodily disease, emphasising the 'figurative implications' of a disease that 'kills or corrupts from within, sometimes unseen from the outside'. ${ }^{7}$ Like Hunter, however, Iyengar views the 'canker' of an ulcerated wound and that of a malignant tumour as 'not readily distinguish[ed]' by early modern medical practitioners. In this chapter, I argue that despite lexical confusion between the two categories, the majority of printed medical texts did in fact show a clear understanding of the difference between 'cankerous' ulcers caused 
by wounds or complaints such as venereal pox, and the more serious disease of cancer.

As will become clear throughout this book, all aspects of the conceptualisation and experience of cancer, from diagnosis to treatment, were closely intertwined. Moreover, theories about the nature and causes of cancer were often uncertain and conspicuously incomplete. Nonetheless, this chapter examines three areas which we might think of as providing the basic framework for an understanding of cancer: discussions of what the disease should be called and why, opinions about where a cancer could occur in the body and what symptoms it might produce, and debates over the efficient causes of the malady. First, I examine the etymology of the term 'cancer' and how the disease of cancer was signified in language. The proliferation of early modern terms for cancer presents, as I discuss, both a challenge for the modern reader and a question over how far this disease can be imagined as a coherent concept. Equally, however, the rich etymological and linguistic 'life' of cancer contributed to the construction of that disease as a singular and unique malady. In the second part of the chapter, I look at the bodily locations of cancer - where it might occur on or in the patient - before outlining some of the most common markers by which this disease was distinguished from more benign lumps and bumps. Finally, I explore the ways in which cancer was imagined as a disease with complex humoral origins, based primarily in the much-maligned humour of melancholy, but often also associated with yellow bile (choler), and the burning or 'adustion' of natural humours into harmful and destructive substances.

\subsection{Cancer or canker? The etymology and terminology of cancerous disease}

What was cancerous disease called in the early modern period? As Bailey's multiple dictionary entries indicate, this question is more complex than it may first appear. Early modern medical practitioners used several different terms to refer to cancer. Some of these terms referred exclusively to the kind of malignant tumours and ulcers we might easily recognize as cancerous today. Others were less precise, sometimes denoting cancerous disease, and at other times referring to any variety of festering sore. Identifying the points of convergence and divergence between these terms is an essential first step in reconstructing beliefs about cancerous disease.

While early modern medical terminology was often bafflingly complex, terms for cancerous disease shared one clear referent. The 
most common names for the malady - 'cancer', 'canker', 'kanker' and 'chancre' - derive from the same etymological root: the Greek 'karkinos'

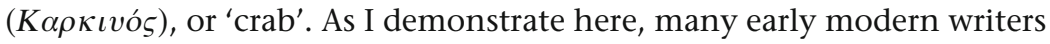
discussing cancer were keenly aware of the term's etymology, and this creatural analogy was influential upon how early modern people diagnosed, and later treated, cancerous disease. Furthermore, it implied that cancerous tumours should be viewed as ontologically independent of the body in which they occurred. Intriguingly, though cancer terminology was unmistakably Greek in origin, it appears that Old English terms for cancerous disease similarly cast the malady as a discrete entity rather than systemic disorder. Pauline Thompson, for example, points out that in Old English, the term used for cancer matched that for the bite of a snake or spider, and the sting of a scorpion. ${ }^{8}$ Writing on medieval understandings of cancer, Luke Demaitre also notes that

the eating action became explicit in several vernaculars, including Old English. A Latin characterization of a cancerous ulcer as having 'taken away' (assumpserat) a patient's lips and nose was translated as 'cancor aet.' Bald's Leechbook defined the disease with a simple synonymy, 'cancer poet is bite.'

As Demaitre's observation makes clear, speakers of one or both languages seemingly recognised the correlation between a biting disease in Old English and a 'grabbing' disease in Latin. This stress on etymology as closely linked to pathology is visible elsewhere in medieval and early modern medicine. ${ }^{10}$ For cancer, however, links between the terminology and the experience of cancerous disease seem to have been particularly strong, materially influencing diagnostic and therapeutic approaches to the malady.

With the meaning of the word 'cancer' so powerfully encoded in the disease's etymology, one might expect that identifying the disease in early modern writings should be a straightforward task. Unfortunately, primary evidence suggests that even for contemporary medical practitioners, this could become a complicated business. In 1684, for example, a translated work by the Swiss physician Théophile Bonet complained about practitioners using the term 'canker' too freely:

The original of the Cheat and Errour is from hence; because Theodorick and Lanfranc, whom Guido [Guy de Chauliac] follows, distinguished a Canker, into a Canker an imposthume, and a Canker an Ulcer. The Canker an Imposthume is the disease so called by Hippocrates, Galen, 
Avicenna and others, rational Physicians and Surgeons: But the Canker an Ulcer (so Guido calls it) is, when by reason of Ulcers or Wounds, irritated by sharp Medicines, bad melancholick humours become adust and troubled... But such Ulcers, though malignant, and often times stubborn, are not yet Cankers, nor ought to be confounded with a Canker, whose Contumacy far surpasses the Malice of all Ulcers. ${ }^{11}$

Bonet's complaint appeared to be about misdiagnosis. At its root, however, was the shifting terminology of cancer, which threatened to destabilise the disease category altogether. Bonet, like many of his contemporaries, used 'canker' instead of 'cancer'. His Guide to the Practical Physician, in which this quotation appeared, made abundantly clear that the disease described was identical with that pinpointed as cancer in other texts. Indeed, Bonet titled this section 'A Cancer, or a Canker'. Clearly, Bonet's 'canker' was merely a variant spelling of cancer which retained the ejective pronunciation from the Latin term, and it was to be used exclusively as such. The same can be said of many contemporary texts which refer to 'cancre', 'kanker' or 'cancor'. Confusion arose, however, because whereas 'cancer' almost always referred to the malignant disease as described throughout this book, 'canker' could, as Bonet complained, signify multiple conditions, of which malignant cancerous disease was only one. These included bodily ulcers and lesions of various kinds, mouth ulcers and venereal sores. As R.W. McConchie observes, this crucial distinction has not always been recognized in literary and medical history:

The existence of an anglicized form alongside the neo-classical form hardly necessitated the desuetude and loss of the other, and the word in foreign form may still have a place in the lexicon. As is often the case pairs develop with differentiated uses, as with cancer-canker, and the omission of one of a pair from the OED helps to obscure this process. ${ }^{12}$

Where supplementary information about a disease is unavailable - as, for example, in many receipt books - negotiating between 'canker-cancer' and 'canker-other' can become a tricky business.

Outside the variations of 'cancer', 'canker' and 'cancre', a separate term was also employed by certain practitioners to describe cancers of the face in particular. Noli-me-tangere, or 'touch me not', was a phrase which played on the widely held belief that interfering with cancers made them worse, as discussed in Chapter 5. From at least the sixteenth into the early eighteenth century, a number of medical writers used the 
phrase alongside 'canker' or 'cancer': asserting, for example, that 'when [cancer] fixes on the Face, 'tis called a Noli me tangere, because that touching irritates it, and makes it a greater Ravage'. ${ }^{13}$ Others, however, believed that noli-me-tangere was a disease similar or related to cancer, but not identical with it. ${ }^{14}$ In the 1706 Chirurgia Curiosa, for instance, German medical practitioner Matthias Gottfried Purmann described noli-me-tangere as a disease which shared many of the characteristics of cancer, including the tendency to ulcerate, but was separate from and 'in some Particulars worse than a Cancer'. ${ }^{15}$ Like 'canker' and 'cancer', this appellation for cancerous disease was intrinsically linked to its symptoms and prognosis. Unlike those terms, however, this phrase presents few challenges to the modern reader. Throughout the early modern period, discussions of the complaint consistently and clearly indicate whether the author uses 'noli-me-tangere' to denote facial cancers, or to signify a separate, though similar, skin complaint.

The terminological instability of cancer certainly presents a challenge to scholars. Nevertheless, it is clear that cancerous disease 'existed' in the early modern period, in the sense of there being a distinctive malady known as 'cancer' which was broadly contiguous with the illness sharing that name today. Early modern medical practitioners generally did not, like some modern physicians, view cancer as a host of separate diseases with similar symptoms. They understood that cancer could occur in different places, and be designated 'womb cancer', 'breast cancer' and so on, but they believed that the same mechanisms were at work in every case. Furthermore, medical writers' stress on the etymology of cancer indicated key directions in the development of the disease concept. By focusing on the crab, they gravitated toward a model of the disease as independent, even sentient. As I discuss here, they used the visual traits of that creature to establish a memorable shorthand by which cancer's most distinctive symptoms were easily recognized. Finally, the activities of the canker-crab promised a sinister and determined adversary, a disease that could bite and grab. Each of these characteristics was to prove influential in the early modern diagnosis, experience and attempted cure of cancers.

\subsection{Symptoms and diagnosis}

When, he, the sore hath searched, clens'd, and dressed,

With Tents, and Plaisters proper thereunto,

(And, all things els, befitting him to do) 
If, on the Wound, his Medicine worketh nought

Of that effect, which, thereby hath been sought;

But, keepes it at a stand, or, makes it worse:

He, presently, begins another course;

And, if that, also, failes him, growes assured,

It is a Cancer, hardly to be cured ${ }^{16}$

In the mid seventeenth-century, at the height of national civil unrest, the poet and pamphleteer George Wither proposed a poetic Opobalsamum Anglicanum to soothe England's woes. The rhetoric underpinning his project, the 'Cure of Some Scabs, Gangreeves and Cancers Indangering the Bodie of this Common-Wealth', is discussed at greater length in Chapter 4 of this book. In this chapter, however, I wish to consider Wither's assertion that cancer could only be 'assuredly' known by its resistance to all forms of cure. This section looks at how early modern medical practitioners attempted to define cancer by describing its most recognizable locations and symptoms - and how they understood the disease as eluding or defying those efforts, presenting a shifting target of which the parameters could never reliably be established.

The question of where in or on the body cancer could occur was central to the diagnostic process. It presents, therefore, an appropriate starting point for examining how medical practitioners and lay people looked at and for this disease. Elsewhere in this book, I make the case for cancer as paradigmatically a disease of the female breasts. For various medical and cultural reasons, I argue, the 'dugs', and to a lesser extent, the womb, of nature's supposedly weaker sex were understood as uniquely vulnerable to this disease. Thoughts of cancer would have come far more readily to a medical practitioner examining, or a patient discovering, a lump in her breast than anywhere else on the body. However, although these locations loomed large in the pathology of cancer, they did not define it absolutely. While attention was certainly concentrated on particular 'cancer-prone' areas, it seems that, given sufficiently compelling symptoms, some medical practitioners were prepared to diagnose cancer in almost any external part of the body. In particular, the 'upper partes about the face, the nosethrills, the eares, the lippes' were identified as being at special risk. ${ }^{17}$ Like the breasts, the soft flesh of the face was deemed vulnerable because of its 'glandulous and spongy' nature, which provided the perfect environment for sluggish humours to coagulate and thicken. ${ }^{18}$ These tissues may also have been common sites of diagnosis for more pragmatic reasons. Facial tumours could not remain hidden for 
long, and even the staunchest sufferer would struggle to ignore the likely disruption to speaking, eating and breathing wrought by a large tumour or ulcer. In severe cases, facial cancers could spread widely, ulcerate and eat away at the patient's bones.

Producing painfully obvious symptoms which, sooner or later, forced sufferers to seek medical advice, it is clear that the vast majority of all diagnosed cancers were on or near the surface of the body, in the breasts, face and skin. Indeed, many early modern authors presented cancer as affecting only these areas. At various points throughout the early modern period, however, individual medical practitioners occasionally discussed and diagnosed cancer in the throat, tonsils, cervix and even the lower part of the intestine. This passage, from the prominent surgeon Richard Wiseman, outlines some of the challenges such diagnoses might pose:

Cancers may also be said to differ as they affect several Parts of the Body, as the Head, Face, Eyes, Nose, the Palate, Tonsils, Throat, Tongue, Jaws or Lips...

Cancers affecting the Uterus and Podex [rectum] may also be distinguished as they are in the interiour or exteriour parts... Those that possess the body of the Uterus, or the upper part of the Rectum intestinum, are not discovered till they have made some progress; in which cases there is a bearing down, with a suppression of Urine. $[\ldots]$

If they be ulcerated, a filthy Sanies will discover it. If it be in the Intestinum rectum, the difficulty and pain in going to Stool will be exceeding great. If the Uterus be cancerated, there will be Fever, nauseousness, anxiety of mind. In some of those who died so diseased I have opened the Body, and found the Uterus preternaturally big and hard: in cutting into it I hav[e] seen it all rotten, Those in the more exteriour parts, whether it be of the Womb or Podex, are sooner discovered, and the Patients are in a greater possibility of being eased of their pains. ${ }^{19}$

Wiseman's description demonstrates that even when practitioners were aware of the possibility of internal cancers, diagnosis depended largely on the cancers either producing externally visible corollaries (tumours around the anus, or fetid 'sanies') or being palpable by the examining practitioner. When cancer invaded the innermost, 'interiour' parts of the body, the impossibility of safely conducting investigative surgery made diagnosis overwhelmingly difficult. As such, tumours of the vital organs 
were hardly discussed at all, and those discussions were usually brief, pointing out the near-impossibility of either identifying or treating the condition in such circumstances.

Knowing where cancers might occur, how was one to discern this disease from the many other skin complaints to which early modern people were susceptible? Given that most cancers were diagnosed on or near the surface of the body, it is unsurprising that visual symptoms were most prominent in medical textbooks' descriptions of cancer, setting the stage for an abiding concern with the (in)visibility of this disease. From the 1580s into the first decades of the eighteenth century, medical practitioners consistently talked about the colour of cancerous tumours, which varied from an unspecified livid hue to 'blackish, and sometimes inclined to black and blue'. ${ }^{20}$ Moreover, it was expected that cancer's livid appearance would accompany a distinctive shape to the tumour, which was both 'rough and unequall' and 'round'; that is, circular, but with an uneven surface appearance. ${ }^{21}$ For medical practitioners writing about and encountering this disease, a round, highly coloured swelling was therefore an immediate source of alarm. Nonetheless, these were characteristics that could and did appear in other, more benign, growths - including undifferentiated 'cankers'. The most definitive of cancer's visual symptoms was one which medical practitioners presented as occurring solely in this disease, and which was taken not only as proof of cancer's presence but as a sign of its 'evil' nature. Darkened blood vessels spreading outward from the suspect tumour seemed to illustrate the spread of malignant matter into the surrounding flesh, and this sign recurred in medical texts across the early modern period as the preeminent visual marker of a dangerous cancer. In the 1587 A Worthy Treatise, for instance, cancer was said to be characterised by 'Veines swollen rounde about with melancholicke bloude'. ${ }^{22}$ Over a century later, the 1698 edition of The Compleat Midwife's Practice similarly noted that breast cancer might be 'known by the crooked windings, and retorted veins that are about it'. ${ }^{23}$

These visual features were firmly established as essential to the diagnosis of cancer, having been common to texts on the subject since the medieval period. ${ }^{24}$ Each one was also consistently reiterated, creating a consensus on the visual signs of a 'true' cancer that was remarkably stable compared to the vigorous debate which surrounded the disease's treatment. Such consensus relied partly upon medical writers' tendency to liberally 'borrow' from one another's work. However, it was also underpinned by the compelling narrative which united diverse 
visual traits with reference to the figure of the crab. Each of the signs noted hitherto was consistently and explicitly aligned with parts of the crab's body. For instance, the roundness of cancer and its colour were both compared with the creature's round and vividly coloured carapace, while the blood vessels extending from the tumour were 'verie like unto the feete of crabbes, descending from the round compasse of their bodies'. ${ }^{25}$

Visual symptoms were central to the diagnosis of cancerous disease, and images of the cancer-crab helped codify those symptoms into a vivid and memorable format. In addition, numerous texts identified pain - specifically, its presence, type and extent - as a deciding factor in distinguishing cancerous from relatively benign scirrhous or phlegmatic tumours. ${ }^{26}$ As the German physician Christof Wirsung vividly described, 'the Canker causeth...great paine and beating, whereof Schirrhus is free'. ${ }^{27}$ Others described an 'exquisite pricking' or 'corrosive, cruel and terrible pain'. ${ }^{28}$ Often coincident with pain as a diagnostic criterion was a 'certaine straunge, and extraordinarie heate' believed to attend cancerous tumours. ${ }^{29}$ Undoubtedly, medical practitioners' interest in heat as a symptom originated in part from Galenic doctrines which positioned health as related to bodily temperature, and to discussions of cancer's cause which pinpointed the 'burning' of melancholy humours as particularly dangerous. In these observations, one can also detect an imaginative fascination with bodily heat. Images of the blood 'in the veines growing hot' depicted the natural and 'vital' warmth of the healthy body transformed into something beyond regulation, for which the inevitable end seemed to be the chill of death. ${ }^{30}$ Furthermore, the pains associated with cancer could, once again, be aligned with the crab. In 1597, for example, physician Peter Lowe asserted that not only did cancers look like crabs, they 'gnaweth, eateth and goeth like this fish' $^{31}$

The use of the crab image as a means of reinscribing the visual and sensory symptoms of cancer thus remained immensely popular throughout the early modern period. The success of this device, however, depended on something more than its fit to cancer's visual characteristics. As an animate creature, the crab lent itself naturally to one of the most defining and enduring characteristics of cancer diagnostics the reading of this disease's symptoms as sentient behaviours. In 1583, physician Philip Barrough asserted that '[s]ome have given [cancer] this name [crab] because it is verie hardly pulled awaie from those members, which it doth lay holde on, as the sea crabbe doth, who obstinately doth cleave to that place which it once hath apprehended', while in 1635 , 
Read added that 'whatsoever it claspeth with the clawes, it holdeth it firmly ... [so] that it seemeth to be nailed to the part'. ${ }^{32}$ The grip of the crab was understood not only as painful but as immensely strong and tenacious, matching precisely the intractability and resistance to cure which was one of cancer's most distinctive features. A renowned French practitioner Pierre Dionis made the connection explicit in 1701 when he explained that "Tis no more possible to extirpate [cancer], than force a Crab to quit what he has grasped betwixt his griping Claws', while in the sixteenth century, Pare deemed the link between the 'tenacity' of cancer and the 'toothed claws' of the crab so instructive that he inserted a picture of the creature into his writing on the subject, to drive home the 'perspicuous' nature of the comparison. ${ }^{33}$

In the figure of the crab, early modern medical practitioners effectively united the diverse visible and invisible symptoms of cancer. Moreover, this practice appears not to have problematized, or been problematized by, understandings of cancer as humoral in origin. This phenomenon is seen amplified in Chapter 3 of this book, where I discuss the casting of cancer as a type of worm or wolf. Although medical practitioners had a good sense of cancer's symptomatology, however, there remained an element of doubt in any diagnosis. As Wither's verse suggested, in order to really be sure that a patient was suffering from cancer, one had to see whether the suspect tumour followed the most distinctive cancerous 'behaviour', that of expanding and spreading throughout the body. Malignancy was, as I shall discuss, fundamental to the very meaning of this disease, setting 'true' cancers apart from the myriad of less dangerous ulcers and neoplasms. Furthermore, it presented a counterpoint to all medical writers' diagnostic criteria. The way to 'know' a cancer was to see it growing; however, that hardly required medical expertise, and once a cancer had grown large, it was much more difficult to treat. Diagnosis therefore presented the first of this disease's many challenges to medical wisdom. Encounters with suspect tumours were not only matters of clinical determination, but of defining human relationships to cancer.

\subsection{Causes of cancer}

By describing cancer's symptoms, and emphasising its crablike 'nature', medical writers sought to distinguish this disease from other tumours and ulcers. Just as importantly, however, these authors attempted to work out why some people got cancer while others remained healthy.

Speculation about the causes of cancer was primarily found in instructional medical textbooks, for several reasons. First, it was deemed 
important for students of physic and surgery to understand how their therapies affected the underlying causes of a disease. Secondly, some medical texts implied that a practitioner's distinction between cancer and diseases with similar symptoms could, and should, be made on the basis of the patient's humoral make-up, something which could be discerned through a raft of signs apparently unconnected to the cancer. John Browne, for example, encouraged medical practitioners to distinguish between cancer and the less serious disease of scirrhus (sometimes thought to precede cancer) by considering that 'a Scirrhus is made by natural Melancholy, which is in the Blood, as the Lee is in the Wine; but a Cancer is not bred from natural, but adust Melancholy' ${ }^{34}$ Maynwaringe went still farther, categorising a whole range of tumours, from Phlegmon to Inflatio, by their humoral cause. ${ }^{35}$ Unusually, his discussion of tumours also dwelt upon internal tumours and the difficulty of their detection; in which scenario any clues offered by the patient's humoral complexion were particularly valuable. ${ }^{36}$

Writers discussing cancer tended to draw broadly similar conclusions about the origins of the disease. Overwhelmingly, and in line with early modern medical orthodoxy, medical practitioners emphasised the provenance of cancer as humoral. More specifically, the disease was believed to arise from the much-maligned substance of black bile, or melancholy, which turned into atra bilis under certain circumstances. Causes of an excess of black bile were numerous, but the humour's effects were well documented. 'Cold and dry, thicke, blacke, sowre', it provoked diseases including epilepsy, ulcers, paralysis and, most notably, the disease of melancholy or melancholia (for clarity, I henceforth use 'melancholia' to describe the disease of melancholic 'depression' and 'melancholy' or 'black bile' to denote the humour). ${ }^{37}$ Although presenting a potential hazard for any early modern body, melancholy, and the maladies associated with it, were associated in particular with the elderly, since with age came a natural 'diminution of spirits and substance' which saw the body becoming colder and drier. ${ }^{38}$ Women, as Chapter 2 of this book details, were thought to be naturally colder than men, and old women were therefore particularly at risk of melancholy complaints. ${ }^{39}$

While excess melancholy could pose a health risk in itself, the vast majority of medical texts did not identify the simple presence of that humour as cancer-causing. Rather, they surmised that it only worked real mischief when either confined to a certain area, transformed into a more harmful substance, or both. Medical practitioners' means of describing these phenomena were diverse, and often confused, but consistently centred upon images of congestion and heating which subverted the 
principles of balance and circulation underlying the Galenic model of good health. Robert Bayfield, for example, asserted in 1662 that 'when this melancholious humor, resembling in proportion the dregs of wine, doth descend and flow into any member, and there abideth compact together, it causeth sometimes the disease called Varices, and sometimes it breedeth a Cancer, as when the same is somewhat cool'd' ${ }^{40}$ Bayfield's comparison of melancholy humour with a waste product, the thickened dregs of wine, was one seen repeated in several other discussions on cancer during the period. In 1583, Barrough similarly wrote that that melancholy 'resembleth the dregges of wine, \& the filthines of oyle', while in 1703, Browne noted that the humour was 'in the Blood, as the Lee is in the Wine'. ${ }^{41}$ There was an obvious internal logic to these claims - since movement and vigour created (and might result from) bodily warmth, melancholy, which occupied the 'cold and dry' corner of the humoral system, was bound to lack those qualities. Certain physicians also linked the sluggish and viscous movement of melancholy to the dysfunction of organs elsewhere in the body, notably the spleen. While the exact role of this organ in the regulation of the humours was often unclear, writers of medical textbooks repeatedly cited 'the infirmity or weakenesse of the spleene in attracting and purging the bloud' as a cause of tumours. ${ }^{42}$ According to Read, this connection was attributable to Galen, who posited that the organ somehow drew 'superfluous naturall melancholy' from other parts of the body, preventing the mischiefs associated with that humour dwelling too long in one place. ${ }^{43}$

However, the persistence with which melancholy was imagined in cancer texts as thick, dark, sluggish and potentially dangerous was not only a product of morphological theory. As Demaitre notes of the medieval period, the conceptualisation of melancholy as related to cancer also 'underscores the suggestive power of humoral physiology' ${ }^{44}$ Black bile possessed a well-established cultural and medical 'biography' by the early modern period. Angus Gowland notes that early modern ideas about black bile, and particularly its role in the generation of madness, were broadly continuous with those of medieval and ancient Greek texts. ${ }^{45}$ Notably, black bile was also subject to the same sort of terminological instability that dogged cancer. ${ }^{46}$ As well as describing a particular substance, or a constitution in which that humour dominated, 'melancholy' also described a disease derivative of, and yet conceptually different from, black bile. Indeed, in his work on early modern selfhood, Charles Taylor sees the relationship between black bile and melancholia as exemplifying the necessity of a historically specific understanding of the relationship between humours and the diseases they caused: 
Melancholia is black bile. That's what it means. Today we might think of the relationship expressed in this term as a psycho-physical causal one. An excess of the substance, black bile, in our system tends to bring on melancholy. We acknowledge a host of such relationships, so that this one is easily understandable to us, even though our notions of organic chemistry are very different from those of our ancestors.

But in fact there is an important difference between this account and the traditional theory of humours. On the earlier view, black bile doesn't just cause melancholy; melancholy somehow resides in it. The substance embodies this significance. ${ }^{47}$

Taylor's claim echoes the observation of Robert Burton, author of the popular Anatomy of Melancholy, that it was almost impossible to say 'whether [melancholia] be a cause or an effect, a Disease, or Symptome'. ${ }^{48}$ It also implies that the relationship between black bile and melancholia, or black bile and cancer, is more fundamental than one might imagine, such that black bile may be said to be the progenitor of both these diseases in an organic sense, imbuing them with its own material qualities. Thus, contemporary discourses about melancholia may have influenced discussions of black bile and its other resultant diseases including cancer.

The properties associated with melancholy and melancholia were almost universally negative. Gowland, for example, argues that a burgeoning tendency in the seventeenth century to ascribe seemingly supernatural powers (such as those of witches) to the effects of melancholia relied in part on 'the common assumption that devils were analogically attracted to interfere with complexionate melancholics because of the dark and semi-excremental nature of the black bile predominating in their bodies' ${ }^{49}$ Similarly, in his discussion of the supposed hallucinatory effects of melancholia, Clark points out that 'balneum diaboli (the devil's bath)' was a common moniker for melancholy humour. ${ }^{50}$ Bridget Gellert Lyons asserts that melancholy's association with Saturn imbued it with certain 'crafty, envious, secretive... maleficent' moral properties, which were particularly useful to contemporary poets and dramatists. ${ }^{51}$ It is easy to see how this information might colour one's reading of cancer, a disease which was itself consistently figured as evil.

Even for those writers who did not view melancholy as malign or devilish, the humour's characterisation as excremental positioned it as dirty and undesirable, a view upheld by Burton's description of melancholy as drawn from the 'faeculent part of nourishment'. ${ }^{52}$ In her work 
on humoralism and cosmology, Gail Kern Paster shows how melancholy accordingly became a watchword for filthiness in drama and polemic as well as medical texts. 'In The Terrors of the Night', she observes, 'Thomas Nashe likens "the thick steaming fenny vapours" of bodily melancholy to waste water'. Just as stagnant puddles 'engendered' foul creatures, so melancholy bred monsters in the imagination. ${ }^{53}$ For the reader of early modern medical texts, the tendency of melancholy to cause cancers by becoming blocked up or stagnating in a certain area was thus to some degree inherent in that humour's dirty, troublesome nature. However, there were further dimensions to the link between melancholy and cancer. Across the early modern period, but particularly from the mid-seventeenth century, printed medical texts consistently pointed to the 'adustion' (heating or burning) of melancholy humours as a crucial step in rendering those humours harmful in general and cancer-causing in particular. Browne, for example, asserted in 1703 that 'a Scirrhus is made by natural Melancholy... but a Cancer is not bred from natural, but adust Melancholy', while in 1635, Read drew a similar conclusion when he stated that cancers commonly appeared in late summer and autumn 'because in these seasons, the melancholick exceedingly increaseth, and humors become adust' ${ }^{54}$ Even while disputing the model, Gendron and Wiseman, both prominent medical authors and practitioners, grudgingly admitted that adustion had become the predominant theory on the generation of cancers. ${ }^{55}$ What adustion actually comprised, and how it occurred, was less clear. Medical practitioners variously ascribed the process to the dysfunction of the liver or spleen, the influence of other humours, the native heat of the body, and external factors such as diet. Most often, as is visible in this passage from Read's Chirurgicall Lectures, they blamed a cornucopia of factors:

There are sundry efficient causes which ingender these humors in our bodies: First, a strong hot distemperature of the liver, which burneth the naturall melancholy and yellow choler, and so hatcheth this Bilis atra. Secondly, according to Galen ... the spleene by reason of its weaknesse and distemperature, doth not draw unto it selfe the superfluous naturall melancholy, and so staying long without its owne proper place it is inflamed and burned. Thirdly, sometimes this humor is caused of the menstruall courses, and Hemorrhodes stopped. Fourthly, verie often an ill diet breedeth this humor (...) An hot aire and perturbations of the mind set forward also this humor. ${ }^{56}$

The external factors - diet, amenorrhea and 'mind set' - identified by Read are discussed elsewhere in this book. In common with many of 
his peers, however, Read identified the causes of adustion with more certitude than specificity. In general, medical practitioners positing a humoral explanation for cancer looked only so far inward - to the level of adust melancholy or atra bilis - before, like Read, they turned their gaze once more toward the environmental factors which aggravated that substance. They were therefore either unable, or saw no good reason, to supply details of exactly what happened inside the body to turn melancholy into these more harmful substances. The neo-Galenic model seems not to have fostered inquiry into the mechanics of each humour's operation, but rather focussed upon their qualitative characteristics. One particularly interesting theory, however, which we can see fleetingly referenced in Read's 'burning of naturall melancholly and yellow choler', was that adust or poisonous forms of melancholy might either have been comprised of several different humours, or of a different humour choler, for example - which mutated into melancholy during the process of adustion. ${ }^{57}$ While this kind of 'compound' melancholy is not evident in most texts on cancer, it is present in a number of discussions of the malady's cause, where a posited link between adust melancholy and choler (yellow bile) often provides a logical bridge between the efficient causes and the characteristics of the disease. ${ }^{58}$ These discussions occurred over the sixteenth, seventeenth and eighteenth centuries, and may have been derived from ancient writings, though this remains unclear. ${ }^{59}$ In his 1684 Adenochoiradelogia, for instance, Browne asserted that 'when [cancer] takes Adust Choler into its cognizance, and this gains better and nearer acquaintance therein, this in time masters the other, and makes the Patient feel the Vigour of its prevalency, by its corrosive, cruel and terrible pain which it brings along with it' ${ }^{60}$ Authors who discussed 'compound' melancholy were clear on the fact that yellow bile changed the character of resulting diseases for the worse. 'Hot, dry [and] bitter', choler was associated with anger and fierceness, and in his 1621 The Anatomy of Melancholy, Burton pinpointed choler as the root of 'brutish', 'rash, raving' varieties of madness. ${ }^{61}$ Moreover, Jennifer Radden notes that, according to Galen, yellow bile was associated with acute diseases and black bile with those of long continuance. ${ }^{62}$ In theories of 'choleric' melancholy, therefore, one sees particularly clearly the marriage between discussions of cancer's cause and its troublesome, 'fierce' character, alongside a ready explanation of how the disease could be both acute in effects and chronic in duration. Furthermore, the language in which such correlations were described once again makes obvious how readily early modern people embraced emotive discourses of the fierce, filthy and mutable nature of certain bodily substances. 
While these theories of adustion may have been lacking in some respects, they retained a largely unchallenged hold over how cancer was imagined until well into the eighteenth century. Iatrochemical language seeped into discourses of cause at various points: in particular, the 'bad' melancholic humour or atra bilis was often described as acidic or acrid. ${ }^{63}$ However, the texts employing these phrases usually used them in conjunction with humoral ideas, seemingly seeking to lend gravitas to their conclusions by employing the newest terminology. In the period under my examination, only a handful of medical writers offered real alternatives to neo-Galenic theories of cancer's cause. Van Helmont's radical theories of disease causation have been well documented by critics and remained unaltered for cancer, positing the mysterious 'Archeus' as the agent of disease. ${ }^{64}$ His approach, however, seems to have had little impact on the majority of medical practitioners or lay writers concerned with this disease. Elsewhere, Wiseman and Gendron provided visibly different alternatives to the above humoral models, but which remained linked to neo-Galenism. Wiseman, for example, scorned traditional ideas about adustion in his Several Chirurgical Treatises, scoffing that 'I cannot imagine what heat these Authors suppose to be in the Body which is capable of making such an Adustion as is here spoken of ${ }^{\prime}{ }^{65}$ He went on, however, to propose a model which integrated both humoral and iatrochemical concepts, stating that cancer-causing humours were 'sharp and corrosive' because of some 'error in the Concoction' involving though in a rather confused manner - 'acid Salts'. ${ }^{66}$ Wiseman's near contemporary, Gendron, went even further, proposing that cancers were 'nothing else... but a change of the Nervous Glandulous Parts, and the Lymphatick Vessels into an uniform, hard, close indissoluble Substance, capable of Increasing and being Ulcerated' ${ }^{67}$ That change, he insisted, was not a humoral one, but was caused by malfunction in the filtrative tissues found in those parts of the body affected by cancer. ${ }^{68}$ As these tissues broke down and compressed into a lump, the vessels around them came under increased pressure, causing them to break down in turn, and so on. Both authors claimed that their models were based on extensive experimentation. ${ }^{69}$ However, while their claims of scientific rigour may have reflected a medical community increasingly invested in the experimental principles of its work, neither author's purported objectivity prevented him from using the same highly emotive terms as were seen in emphatically humoralist texts on the genesis of cancer. Of the cancerous tumour, Gendron stated that 'Nature, if I may so say, is out of order', and continued the use of organic and even anthropomorphic images in talking of a cancerous ulcer 'which ... destroys its own 
Substance, by a Progressive Putrefaction' ${ }^{70}$ Similarly, Wiseman slipped into well-worn descriptions of cancer as anthropomorphically 'rebellious' and 'malign'. ${ }^{71}$

Clearly, the vast majority of writers on cancer adhered broadly to theories which positioned adust melancholy as the immediate cause of the disease. Even some of those who ostensibly rejected this model incorporated aspects of the theory into their alternative theses. What made this idea such an appealing and influential one, and how did it affect the perception of cancer's pathology more generally? As noted earlier, such theories accessed the wealth of imagery attendant on melancholy as part of both medical and broader cultural discourses. Moreover, adust melancholy offered solutions to a number of troubling aspects of the humoral model of cancer's causation. That is, it helped to explain why cancer patients frequently lacked any melancholic symptoms prior to the onset of their cancer, by arguing that patients suffered less from an excess of the humour than an accident in its formulation. It also avoided blaming serious illness on a substance which was supposedly natural and native to the body, as well as clarifying - either through the 'heating' or 'choleric' models - why these swellings, caused by a cold and dry humour, were often so hot to the touch.

As importantly, adust melancholy carried a cultural freight which expanded in many respects on negative beliefs about 'normal' melancholy. ${ }^{72}$ This mid-seventeenth-century poem on 'Religion', for example, picked up the well-worn idea of black bile as the humour of witches and devils and reapplied that notion to adust melancholy in particular. 'Evill Spirits', wrote the author,

have been, in Adust,

Black Choler, sayd, to find a Tempting Gust

(From whence their own Familiar-Imps, like Leaches

Are Nursd, and Suckled, at the Teats of witches) ${ }^{73}$

Such suspicious attitudes toward adust melancholy were repeated in the loaded language of medical texts. The French medical practitioner Paul Dubé, for example, identified adust humours as 'nothing else than a natural Humour degenerated from its natural Disposition, and turn'd into a foreign form', adding that such humours proved particularly 'Malignant' and troublesome. ${ }^{74}$ According to this rhetoric, adust melancholy was decisively alien to the body, having been utterly transformed from the sometimes harmful but ultimately native substance of ordinary 
melancholy. That concern was reiterated in Browne's assertion that 'Cancer is not bred from natural, but adust Melancholy': adustion was a product of which the organic genesis was implied in that term 'bred', but which was, like cancer itself, an unnatural progeny. ${ }^{75}$ Bonet, citing the prominent medieval writer Guy de Chauliac as his influence, likewise summarised adust melancholy in emotive terms. '[B]ad melancholick humours', he wrote, 'become adust and troubled, and are drawn...to that place, where they putrefy, grow hot, and acquire an acrimony and poisonous quality, whence there is an increase of the evil disposition, and it becomes a Canker'. ${ }^{76}$ One sees in this passage the natural conclusion of the discourses positioning adust melancholy as 'unnatural': the casting of that humour as a poison, created by the body but now, like the cancer itself, hostile to it. Furthermore, the adustion of the humours marked, for Bonet, their transition from merely 'bad' to the anthropomorphic terms of 'troubled' and 'evil', sentiments which, as Chapter 4 demonstrates, were common among medical practitioners struggling to express the malignancy of the disease.

Beliefs about the humoral origins of cancerous disease played a crucial part in how cancer was imagined by both medical practitioners and lay people. Unsurprisingly, it also shaped therapeutic responses to cancer. As I shall discuss, humoral medicine was designed to redress quantitatively unbalanced humours; degenerate and unnatural atra bilis was qualitatively different, and therefore outside the bounds of medical wisdom. Discussions of cancer's origins viewed the mysterious and malign properties of adust melancholy as integrated into the qualities and 'behaviours' of the disease itself, creating a formidable, changeable adversary.

\section{Conclusion}

This chapter set out to answer an apparently simple query. What, I asked, did early modern people talk about when they talked about cancer? The firmest conclusion of the chapter is that this is a question worth posing, for we have seen the degree to which the concept of cancer was at once a malleable construction, and a disease of which the fundamental 'character' remained stable even as medical practitioners debated its specifics. Visible throughout early modern sources on the naming, diagnosis and causes of cancer is the urge to turn this disease from a disparate and confusing collection of incidences into a singular and understandable entity. Thus, the often confusing language of cancer consistently returned to a single image, that of a biting creature; the symptoms of 
the disease were collected into one creature, the crab, and discussions of cause overwhelmingly offered a humoral explanation.

Those unifying urges could only do so much, and anxieties about the un-knowability of this subject consistently resurfaced. Nonetheless, the tone and content of these primary texts has shown that cancer was a disease understood through shaping discourses about its actions and characteristics rather than by the means, now more familiar to us, of a pathology based on its cellular and chemical properties. These discourses would prove influential upon every aspect of early modern conceptualisation and experience of cancer. Belief in humoral causation would affect which therapies were administered for the disease and lead practitioners to look at dietary, environmental and emotional circumstances as they pondered why some people suffered cancers whilst others stayed healthy. Meanwhile, observation of cancer's crab-like characteristics, and speculation about its roots in the 'evil', unclean and gendered substance of melancholy were to play a shaping role in discussions of the disease's nature.

cc (i) Except where otherwise noted, this work is licensed under a Creative Commons Attribution 4.0 Unported License. To view a copy of this license, visit https://creativecommons.org/version4 